\title{
Excess free fructose, high-fructose corn syrup and adult asthma: the Framingham Offspring Cohort
}

\author{
Luanne R. DeChristopher ${ }^{1 *}$ and Katherine L. Tucker ${ }^{2}$ \\ ${ }^{1}$ Independent Researcher, Eugene, OR 97405, USA \\ ${ }^{2}$ Department of Biomedical and Nutritional Sciences, University of Massachusetts Lowell, Lowell, MA O1854, USA
}

(Submitted 18 October 2017 - Final revision received 5 January 2018 - Accepted 22 January 2018 - First published online 28 March 2018)

\begin{abstract}
There is growing evidence that intakes of high-fructose corn syrup (HFCS), HFCS-sweetened soda, fruit drinks and apple juice - a high-fructose $100 \%$ juice - are associated with asthma, possibly because of the high fructose:glucose ratios and underlying fructose malabsorption, which may contribute to enteral formation of pro-inflammatory advanced glycation end products, which bind receptors that are mediators of asthma. Cox proportional hazards models were used to assess associations between intakes of these beverages and asthma risk, with data from the Framingham Offspring Cohort. Diet soda and orange juice - a $100 \%$ juice with a 1:1 fructose:glucose ratio - were included for comparison. Increasing intake of any combination of HFCS-sweetened soda, fruit drinks and apple juice was significantly associated with progressively higher asthma risk, plateauing at 5-7 times/week $v$. never/seldom, independent of potential confounders (hazard ratio 1.91, $P<0 \cdot 001$ ). About once a day consumers of HFCS-sweetened soda had a $49 \%$ higher risk $(P<0 \cdot 011)$, moderate apple juice consumers $(2-4$ times/week) had a $61 \%$ higher risk $(P<0.007)$ and moderate fruit drink consumers had a 58\% higher risk $(P<0 \cdot 009)$, as compared with never/seldom consumers. There were no associations with diet soda/orange juice. These associations are possibly because of the high fructose:glucose ratios, and fructose malabsorption. Recommendations to reduce consumption may be inadequate to address asthma risk, as associations are evident even with moderate intake of these beverages, including apple juice - a $100 \%$ juice. The juice reductions in the US Special Supplemental Nutrition Program for Women, Infants, and Children in 2009, and the plateauing/decreasing asthma prevalence (2010-2013), particularly among non-Hispanic black children, may be related. Further research regarding the consequences of fructose malabsorption is needed.
\end{abstract}

Keywords: Glycation: Excess free fructose: High-fructose corn syrup: Fructositis: Receptor of advanced glycation endproducts: Apple juice: Fruit drinks

There is growing evidence that intakes of high-fructose corn syrup (HFCS) ${ }^{(1)}$, HFCS-sweetened soft drinks ${ }^{(2-5)}$ and fruit drinks ${ }^{(3,4)}$ are associated with asthma. Results of a rigorous food elimination diet with $\mathrm{HFCS}^{(1)}$ - a scientifically recognised method to assess food sensitivity recommended by a panel of experts, established by the National Institute of Allergy and Infectious Diseases, often referred to as 'the Guidelines ${ }^{,(6)}$ provided evidence that intake of HFCS-sweetened foods and beverages is associated with airway mucus hypersecretion, asthma, chronic bronchitis and idiopathic joint pain ${ }^{(1)}$. Recent epidemiological studies, by the US Centers for Disease Control (CDC), provided evidence that US high-schoolers $(n 15960)^{(2)}$ who regularly consumed HFCS-sweetened soda were $64 \%$ more likely to have asthma than never consumers, independent of smoking and BMI. Researchers suggested that the link may be because of the preservatives, on the basis of their review of prior research ${ }^{(2)}$. However, a review of these prior studies showed no strong scientific evidence that preservatives in soda are associated with chronic respiratory conditions ${ }^{(7)}$. Importantly, the preservatives in HFCS-sweetened soda are also in diet soda, and diet soda has not been found to be associated with asthma ${ }^{(7)}$. Other epidemiological research studies are consistent with the possibility that the associations may be with the HFCS in US soft drinks. For example, in New Zealand, soda is sweetened with sucrose ${ }^{(8)}$, and in a 2005 study (the International Study of Asthma and Allergies in Childhood) researchers found no association between 'fizzy' drinks and asthma $^{(9)}$. In an Australian study (where soda is sweetened with sucrose), intake ( $>0.5$ litre/d) of soft drinks was associated with asthma, among current smokers. There were no associations

Abbreviations: AGE, advanced glycation end products; CDC, US Centers for Disease Control; EFF, excess free fructose; enFruAGE, extracellular newly identified fructose associated advanced glycation end products; FHS-OS, Framingham Heart Study Original-Cohort Study; HFCS, high-fructose corn syrup; HR, hazard ratio; NHANES, (US) National Health and Nutrition Examination Survey; SSB, sugar-sweetened beverages; T2D, type 2 diabetes.

* Corresponding author: L. R. DeChristopher, email luanne.dechristopher@gmail.com 
among non/ex-smokers, suggesting that the link was due to smoking rather than the soda (smokers may have been more likely to drink soda than non/ex-smokers) ${ }^{(10)}$.

A case study with HFCS food elimination results led to the development of a biochemical hypothesis that may explain the asthma association. According to the 'fructositis' hypothesis, underlying fructose malabsorption results in the intestinal formation of pro-inflammatory advanced glycation end products (enFruAGE) between unabsorbed fructose and partially digested dietary proteins that, once absorbed, promote asthma ${ }^{(1)}$. The intestinal environment after a meal may be highly conducive to enFruAGE formation ${ }^{(7)}$, as the phosphates from phosphoric acid ${ }^{(11-13)}$ in soda ${ }^{(14,15)}$ and the bicarbonate ${ }^{(12,13)}$ in pancreatic juice are catalysts of the Maillard reaction, which produces pro-inflammatory advanced glycation end products (AGE) ${ }^{(11-13)}$. Researchers recently tested this hypothesis. They found that fructose, as remains in the digestive tract of fructose malabsorbers, forms AGE - under conditions compatible with the intestines - within a time frame well within the window of digestion, but not with glucose ${ }^{(16,17)}$. Notably, fructose malabsorption occurs after consumption of foods and beverages with high fructose:glucose ratios, ${ }^{(18-21)}$ including HFCS $^{(22-24)}$, agave syrup ${ }^{(25,26)}$, crystalline fructose and apple juice ${ }^{(27)}$, but not after consumption of sucrose or equivalent monomers of fructose and glucose ${ }^{(18-21)}$. Importantly, researchers from the University of California found that fructose to glucose ratios $\left(1 \cdot 9: 1^{(28)}\right.$ and $\left.1 \cdot 5: 1^{(29)}\right)$ in popular US sodas exceeded levels that are generally recognised as safe $(1 \cdot 2: 1)^{(22-24)}$, which provided evidence that there has been more excess free fructose (EFF) in the US food supply than previously thought. Notably, HFCS has been ubiquitous in the US food supply since the $1990 \mathrm{~s}^{(30-34)}$. Further evidence of a possible role for an enteral FruAGE/receptors of advanced glycation end products (RAGE) pathway in asthma arose when researchers discovered that RAGE, which are highly concentrated in the lungs ${ }^{(35)}$, are mediators of asthma ${ }^{(36)}$.

We recently epidemiologically tested whether intake of high fructose:glucose ratios was associated with asthma using US nationally representative health survey data (National Health and Nutrition Examination Survey (NHANES) $)^{(4)}$. If a high fructose: glucose ratio (EFF) and fructose malabsorption underlie the HFCS/soda/asthma link, then, in addition to HFCS-sweetened soda and fruit drinks, apple juice - owing to its $\geq 2: 1$ fructose to glucose ratio ${ }^{(27)}$ - would also be associated with asthma. Our results support this hypothesis. Children ( $n$ 1961) who moderately (2-4 times/week) consumed apple juice - a 100\% juice - were more than two and a half times as likely to have asthma, and children who regularly consumed any combination of HFCS-sweetened soda, fruit drinks and apple juice were five times more likely to have asthma, as compared with seldom/never consumers, independent of sex, BMI and total energy intake. There was no association with orange juice ${ }^{(4)}-\mathrm{a} 100 \%$ juice with a 1:1 fructose:glucose ratio ${ }^{(27)}$. There were no associations with atopic dermatitis $^{(4)}$. We also found that adults ( $n$ 2801) who regularly consumed HFCS-sweetened soda were nearly twice as likely to have chronic bronchitis, independent of smoking, and exposure to in-home smoke, but not with diet drinks ${ }^{(37)}$.

Results from two longitudinal cohorts provided further evidence that asthma may be associated with high fructose juice (e.g. apple juice) intake ${ }^{(5,38,39)}$. In a US study ( $n$ 1111), asthma risk was $34 \%$ higher among children who regularly consumed
$100 \%$ juice (exclusive of orange juice), as compared with seldom/never consumers. There was no association with orange juice $^{(5)}$. In a Danish study, children ( $n$ 2406) who frequently consumed $100 \%$ juice (type not distinguished) were twice as likely to have asthma than never/seldom consumers ${ }^{(38,39)}$.

\section{Methods}

\section{Study objectives}

Epidemiological studies with longitudinal data are lacking. Therefore, we tested the hypothesis that consumption of HFCSsweetened soda, fruit drinks and apple juice, but not orange juice or diet soda, increases asthma risk, independently of potential confounders. Fruit drinks were included, as many varieties contain apple juice and are sweetened with HFCS. Survival analysis was conducted with longitudinal data from the Framingham Heart Study-Offspring cohort (FHS-OS) ${ }^{(40)}$. The FHS-OS was ideally suited to this investigation, as participants were enrolled starting in 1971 - before widespread use of $\operatorname{HFCS}^{(23,24,40,41)}$ - and were followed up for $>30$ years ${ }^{(40)}$. US soft drink producers switched from the use of sucrose to HFCS in non-diet soda around $1984^{(33,34,41,42)}$.

\section{Participants}

The FHS-OS is a prospective study with offspring (5013) of the Original Cohort (Framingham, Massachusetts). Participants were adult, predominantly non-Hispanic White men and women, with a mean age of 47.9 (SD 9.7); $39 \%$ were overweight and $17 \%$ were obese at baseline. Participants were medically examined and responded to health questions approximately every 4 years, with the exception of an 8-year gap between examinations 1 and 2. Food and beverage intake frequency was obtained via the Willett Food Frequency Questionnaire (FFQ), beginning with examination $3(1984)^{(40)}$. This study focused on data from examinations 3-7 (1984-2001) - a period with approximately 17 follow-up years. Participants were excluded from analyses if they self-reported bronchodilator/aerosol use and/or history of asthma/wheezing during examinations 1 and 2 - that is 'have you had asthma/wheeze (since last exam)'. Onset of risk was defined as 1984, as it coincides with a shift by major US soft drink producers from the use of sucrose to $\operatorname{HFCS}^{(33,34,41,42)}$. The FHS-OS was approved by the US-National Heart, Lung and Blood Institute of the National Institutes of Health. Participants gave written consent.

There were between 2692 and 2696 participants with complete responses to analyses questions, depending upon the beverage. A flow chart showing exclusions is provided as the online Supplementary Material.

\section{Beverage intake}

We analysed intake frequency of non-diet soda - the high-EFF beverage most consumed by US adults ${ }^{(43,44)}$ - fruit drinks, apple juice and any combination of these beverages (referred to as ttlEFF), as self-reported at each examination via the Willett $\mathrm{FFQ}^{(40)}$. During the study period, HFCS was the main sweetener in US soda ${ }^{(45)}$. Intake frequencies were estimated for 
examination 4 (average of examinations 3 and 5), as examination 4 lacked an FFQ. For individual analyses, intake frequencies were reduced from seven to four ( $\leq$ once/week, 2-4 times/week, 5-7 times/week and > once a day), except for individual analyses with apple juice and fruit drinks, with three levels ( $\leq$ once/week, 2-4 times/week, $\geq 5$ times/week), as fewer people reported consumption >once a day. To analyse intake frequencies for any combination of non-diet soda, fruit drinks and apple juice, the following values were assigned, based on responses for each beverage, and then summed per respondent: 0.016 , that is $0.5 / 30$, for never or $<1 /$ month; 0.066 , that is $2 / 30$, for $1-3$ times/month; $0 \cdot 143$, that is $1 / 7$, for 1 time/week; $0 \cdot 429$, that is $3 / 7$, for $2-4$ times/week; $0 \cdot 857$, that is $6 / 7$, for $5-7$ times/week; $2 \cdot 5$, for $2-3$ times/d; and 4 , for $\geq 4$ times/d. Sums were then divided into quintiles to establish five intake frequencies for any combination of HFCS-sweetened soda, fruit drinks and apple juice. For comparison, we also analysed diet soda and orange juice - a juice with a 1:1 fructose:glucose ratio $^{(27)}$. The FFQ directed participants to estimate their usual intake of a standardised portion of a given food item. The suggested serving size for fruit and soft drinks was a can or glass, as compared with a small glass for juice ${ }^{(40)}$.

\section{Ascertainment of end points}

Incident asthma was defined as self-reported asthma (at each examination), including wheezing or asthma (have you had asthma/wheeze since the last examination of short duration, long duration or with respiratory infections). Two analysis models were used. The first model analysed asthma risk on the basis of the first self-reported incidence of asthma - after risk onset. The second model analysed multiple end points, and it reflects risks associated with persistent (recurring) asthma.

\section{Potential confounders}

Potential confounders were selected based on existing research ${ }^{(2-5)}$. Adjustments were made for sex, age, history of smoking, education level (non-high-school graduate; high-school graduate; college; post baccalaureate) and time-varying covariates, including interim smoking (smoked cigarettes/cigars/pipes since the last examination), total energy intake and BMI (continuous variable) - a comorbidity of asthma. We also adjusted for type 2 diabetes (T2D) - as recent research indicates that T2D is a comorbidity of asthma, for reasons that remain unclear ${ }^{(46)}$. T2D status was based upon fasting glucose concentration $\geq 6.99 \mathrm{mmol} / \mathrm{l}(\geq 126 \mathrm{mg} / \mathrm{dl})$, T2D treatment status or both. If fasting glucose was unavailable, a participant was T2D positive if non-fasting blood glucose was $\geq 11.1 \mathrm{mmol} / \mathrm{l}(\geq 200 \mathrm{mg} / \mathrm{dl})$ or there was a known history of T2D. Diabetes status was updated if diabetes status was missing and it was provided in the previous examination ${ }^{(40)}$.

\section{Statistical analysis}

There were 445 exclusions owing to self-reported bronchodilator/ aerosol use or history of asthma/wheezing before examination 3 . Participants with implausible energy intakes ( $n$ 160), as established by the FHS ( $<600$ and $>4000$ ), were also excluded from the analyses. Cox proportional hazards models with time-varying covariates, with time on study as the time scale, were used for analyses. After verifying proportional hazards assumptions by using the Schoenfeld and scaled Schoenfeld residuals for the models - as a whole and individually, including plots for each predictor $(P \geq 0.05)$ - we examined incident asthma over approximately 17 years of follow-up, using multivariableadjusted Cox proportional hazards models to estimate hazard ratios (HR). Risk onset was defined as 11 years (1984) from the mid-point (1973) of enrolment (1971-1975). Person-time was calculated from baseline (1983-1987) to examination 7 (1998-2001), death, loss to follow-up, incident asthma (model 1) or persistent/recurring asthma (model 2).

Covariates were updated at each time point (examinations 3-7). For missing data, the last value was carried forward for BMI, smoking status and T2D status - a protocol used in existing sugar-sweetened beverages (SSB) research ${ }^{(47)}$. For total energy intake, subsequent values were used if the prior examination value was missing, as examination 5 had 304 missing values and examination 6 had 132 missing values. Total energy intake for examinations 3 and 4 were estimated by averaging values from examinations 5, 6 and 7, as total energy intake was not available in the data set for examinations 3 and 4. Analyses of individual beverages included additional adjustments for the other high-EFF beverages, to enable independent assessment of each high-EFF beverage. For example, the HR for non-diet soda reflects asthma risk, which is independent of fruit drinks and apple juice. Within each model, potential mediators were analysed in two ways: the first included age, sex, education level, total energy intake, BMI, history of smoking and interim smoking as potential confounders, and the second included further adjustment for T2D status, to assess associations independent of blood glucose. Stata version 13.1 was used and a two-tailed $P$ value $<0.05$ with $95 \%$ CI that did not include 1 was considered statistically significant.

\section{Results}

\section{Baseline characteristics}

A higher percentage of participants frequently ( $\geq 5$ times/week) consumed orange juice ( $43.6 \%$ ) as consumed HFCS-sweetened soda $(31 \%)$ and diet soda $(37 \cdot 8 \%)$. Nearly half of the participants $(46.7 \%)$ reported intake of ttlEFF approximately once or more per day at baseline (examination 3 ). Within this combination, the percentage of respondents who regularly ( $\geq 5$ times/ week) consumed non-diet soda $(31 \%, n$ 2394) was higher than apple juice $(5 \cdot 1 \%, n$ 2392) or fruit drinks (8.1\%, $n$ 2388) (Table 1). Men consumed non-diet soda or any combination of non-diet soda, fruit drinks and apple juice more frequently than women, and frequent consumption of these beverages was associated with higher prevalence of current/recent smoking, whereas women were more likely to consume diet soda. Frequent ( $\geq 5$ times/week) orange juice consumers were less likely to have smoked since the prior examination than frequent consumers of non-diet soft drinks (Table 2). Increasing consumption of all sugar-containing beverages was associated with higher total energy intakes ranging from approximately $7113 \mathrm{~kJ}$ (1700 kcal) for $\leq$ once/week to approximately $8786 \mathrm{~kJ}$ (2100 kcal) for more than once/d consumption. 
Table 1. Baseline characteristics of adults aged $24-72$ years in the Framingham Offspring Cohort $-1984^{*}$

(Mean values and standard deviations)

\begin{tabular}{|c|c|}
\hline$n$ & 2396 \\
\hline \multicolumn{2}{|l|}{ Age (years) } \\
\hline Mean & 51.5 \\
\hline SD & $9 \cdot 8$ \\
\hline Sex (\% male) & $46 \cdot 5$ \\
\hline \multicolumn{2}{|l|}{ BMI $\left(\mathrm{kg} / \mathrm{m}^{2}\right)$} \\
\hline Mean & $26 \cdot 0$ \\
\hline SD & 4.5 \\
\hline$\leq$ Target weight $\leq 24.9(\%)$ & 38.4 \\
\hline Overweight $>24.9-\leq 29.9(\%)$ & 41.0 \\
\hline Obese >29.9 (\%) & $20 \cdot 6$ \\
\hline \multicolumn{2}{|l|}{ Energy intake $(\mathrm{kJ} / \mathrm{d})$} \\
\hline Mean & 7761 \\
\hline SD & 2326 \\
\hline \multicolumn{2}{|l|}{ Energy intake $(\mathrm{kcal} / \mathrm{d})$} \\
\hline Mean & 1855 \\
\hline SD & 556 \\
\hline \multicolumn{2}{|l|}{ Education level (\%) } \\
\hline $0-11$ years $(<$ high-school graduate $)$ & $5 \cdot 2$ \\
\hline 12 years (high-school graduate) & 33.2 \\
\hline $13-15$ years (some college) & $28 \cdot 3$ \\
\hline $16+$ years ( $\geq$ college graduate) & $33 \cdot 3$ \\
\hline Diabetes (\% yes) & 3.7 \\
\hline History of smoking (\% yes) & $60 \cdot 1$ \\
\hline Smoked cigarettes since the past examination (\% yes) & $18 \cdot 8$ \\
\hline Smoked cigars/pipes since the past examination (\% yes) & $<1.0$ \\
\hline \multicolumn{2}{|l|}{ Intake frequency ttIEFF (\%) ( $n$ 2396) } \\
\hline$<3$ times/months & $11 \cdot 7$ \\
\hline About once/week & $19 \cdot 3$ \\
\hline 2-4 times/week & $22 \cdot 3$ \\
\hline About once/d & $25 \cdot 9$ \\
\hline$>$ Once/d & $20 \cdot 8$ \\
\hline \multicolumn{2}{|l|}{ Intake frequency non-diet soda (\%) ( $n$ 2394) } \\
\hline$\leq$ Once/week & $49 \cdot 5$ \\
\hline 2-4 times/week & $19 \cdot 5$ \\
\hline 5-7 times/week & $17 \cdot 2$ \\
\hline$>$ Once/d & $13 \cdot 8$ \\
\hline \multicolumn{2}{|l|}{ Intake frequency diet soda (\%) $(n$ 2394) } \\
\hline$\leq$ Once/week & $48 \cdot 1$ \\
\hline 2-4 times/week & $14 \cdot 1$ \\
\hline 5-7 times/week & $15 \cdot 3$ \\
\hline$>$ Once/d & $22 \cdot 5$ \\
\hline \multicolumn{2}{|l|}{ Intake frequency orange juice (\%) ( $n$ 2392) } \\
\hline$\leq$ Once/week & $32 \cdot 1$ \\
\hline 2-4 times/week & $24 \cdot 3$ \\
\hline 5-7 times/week & $36 \cdot 9$ \\
\hline$>$ Once/d & $6 \cdot 7$ \\
\hline \multicolumn{2}{|l|}{ Intake frequency apple juice (\%) ( $n$ 2392) } \\
\hline$\leq$ Once/week & 79.5 \\
\hline 2-4 times/week & $15 \cdot 4$ \\
\hline$\geq 5$ times/week & $5 \cdot 1$ \\
\hline \multicolumn{2}{|l|}{ Intake frequency fruit drinks (\%) ( $n$ 2388) } \\
\hline$\leq$ Once/week & $82 \cdot 0$ \\
\hline 2-4 times/week & 9.9 \\
\hline$\geq 5$ times/week & $8 \cdot 1$ \\
\hline
\end{tabular}

ttIEFF, combination of high-fructose corn syrup-sweetened soft drinks, fruit drinks and apple juice.

* Characteristics are based upon self-reported responses to the medical and FFQ administered at baseline (1984)

\section{Relationship with asthma}

Greater intake of any combination of HFCS-sweetened soda, fruit drinks and apple juice was significantly associated with progressively higher asthma risk, rising from $59 \%$ higher for moderate (2-4 times/week) consumers to a plateau of $89 \%$ higher among 5-7 times/week $v$. never/seldom consumers

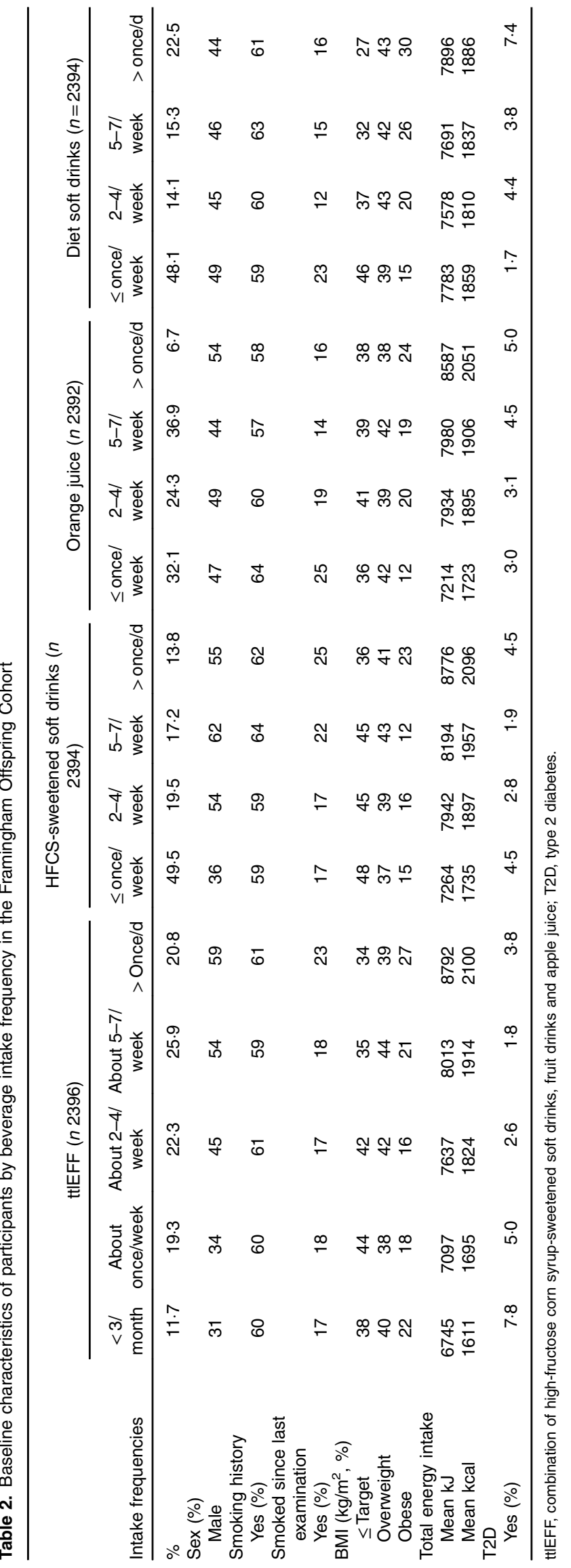


Table 3. Asthma risk according to beverage consumption in adults, the Framingham Offspring Cohort (Hazard ratios (HR) and $95 \%$ confidence intervals)

\begin{tabular}{|c|c|c|c|c|c|c|}
\hline \multirow[b]{2}{*}{$\underline{\text { Asthma risks } \dagger}$} & \multicolumn{3}{|c|}{ Cox proportional hazards model 1} & \multicolumn{3}{|c|}{ Cox proportional hazards model 2} \\
\hline & HR & $95 \% \mathrm{Cl}$ & $P$ & $\mathrm{HR}$ & $95 \% \mathrm{Cl}$ & $P$ \\
\hline & \multicolumn{3}{|c|}{$\begin{array}{l}\text { Adjusted for sex, age, ever smoked, education } \\
\text { level and time-varying covariates such as } \\
\text { BMI, smoking, total energy intake }\end{array}$} & \multicolumn{3}{|c|}{ Further adjusted for diabetes, type 2} \\
\hline \multicolumn{4}{|c|}{$n 2696$, no. of obs $=8864$} & \multicolumn{3}{|c|}{$n 2696$, no. of obs 8862} \\
\hline$<3$ times/month & Ref. & & & Ref. & & \\
\hline About once/week & 1.21 & $0.85,1.72$ & 0.284 & 1.22 & $1.03,1.85$ & 0.258 \\
\hline About 2-4 times/week & 1.59 & $1 \cdot 12,2 \cdot 25$ & $0.009^{*}$ & 1.61 & $1.36,2.49$ & $0.008^{*}$ \\
\hline About 5-7/week & 1.89 & $1 \cdot 36,2 \cdot 62$ & $0.000^{*}$ & 1.91 & $1.37,2.66$ & $0.000^{*}$ \\
\hline$>$ Once/d & 1.40 & $0.98,2.00$ & $0.067^{\circ}$ & 1.41 & $0.99,2.02$ & $0.058^{\circ}$ \\
\hline \multirow{2}{*}{ 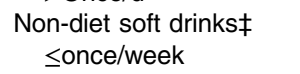 } & \multicolumn{3}{|c|}{ Further adjusted for FD and AJ } & \multicolumn{3}{|c|}{ Further adjusted for FD and AJ } \\
\hline & \multicolumn{3}{|l|}{ Ref. } & \multicolumn{3}{|l|}{ Ref. } \\
\hline $2-4$ times/week & 0.99 & $0.73,1.34$ & 0.960 & 1.00 & $0.73,1.35$ & 0.980 \\
\hline 5-7 times/week & 1.48 & $1.09,2.01$ & $0.011^{*}$ & 1.49 & $1 \cdot 10,2 \cdot 02$ & $0.011^{*}$ \\
\hline \multirow{2}{*}{$\begin{array}{c}>\text { Once/d } \\
\text { Fruit drinksł }\end{array}$} & 0.94 & $0.68,1.31$ & 0.726 & 0.94 & $0.71,1.36$ & 0.736 \\
\hline & \multicolumn{3}{|c|}{ Further adjusted for ndSoda and AJ } & \multicolumn{3}{|c|}{ Further adjusted for ndSoda and AJ } \\
\hline sonce/week & \multicolumn{3}{|l|}{ Ref. } & \multicolumn{3}{|l|}{ Ref. } \\
\hline $2-4$ times/week & 1.58 & $1 \cdot 12,2 \cdot 22$ & $0.009^{*}$ & 1.58 & $1 \cdot 12,2 \cdot 23$ & $0.009^{*}$ \\
\hline$\geq 5$ times/week & 0.85 & $0.52,1.38$ & 0.506 & 0.85 & $0.52,1.38$ & 0.532 \\
\hline Apple juiceł & \multicolumn{3}{|c|}{ Further adjusted for ndSoda and FD } & \multicolumn{3}{|c|}{ Further adjusted for ndSoda and FD } \\
\hline$\leq$ Once/week & Ref. & & & Ref. & & \\
\hline 2-4 times/week & 1.61 & $1 \cdot 14,2 \cdot 28$ & $0.007^{\star}$ & 1.61 & $1 \cdot 14,2 \cdot 28$ & $0.007^{\star}$ \\
\hline$\geq 5$ times/week & 1.08 & $0.65,2.09$ & 0.792 & 1.08 & $0.60,1.94$ & 0.793 \\
\hline \multicolumn{7}{|l|}{ Diet soda } \\
\hline$\leq$ Once/week & Ref. & & & Ref. & & \\
\hline 2-4 times/week & 1.00 & $0.72,1.40$ & 0.974 & 1.00 & $0.72,1.40$ & 0.985 \\
\hline 5-7 times/week & 0.83 & $0.57,1.21$ & 0.343 & 0.83 & $0.57,1.21$ & 0.334 \\
\hline$>$ Once/d & 0.94 & $0.73,1.21$ & 0.637 & 0.93 & $0.72,1.20$ & 0.585 \\
\hline \multicolumn{7}{|l|}{ Orange juice } \\
\hline sonce/week & Ref. & & & Ref. & & \\
\hline 2-4 times/week & 0.99 & $0.73,1.33$ & 0.931 & 0.99 & $0.73,1.33$ & 0.931 \\
\hline 5-7 times/week & $1 \cdot 12$ & $0.88,1.43$ & 0.350 & $1 \cdot 12$ & $0.88,1.43$ & 0.350 \\
\hline >Once a day & 0.78 & $0.44,1.38$ & 0.391 & 0.78 & $0.44,1.38$ & 0.392 \\
\hline \multicolumn{7}{|c|}{ 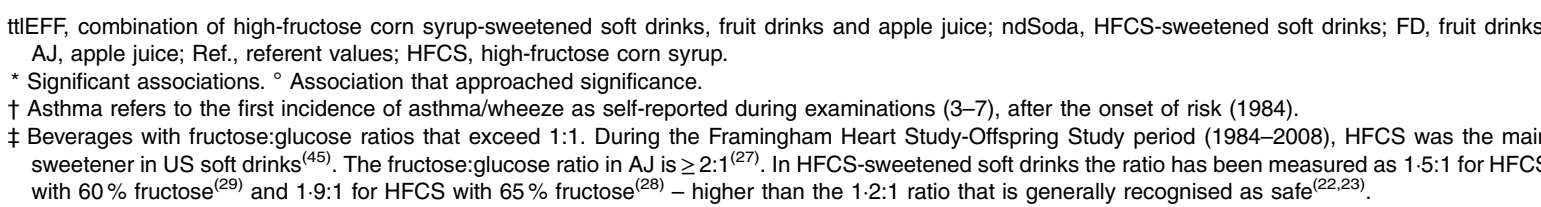 } \\
\hline
\end{tabular}

$(P<0.001)$, independent of potential confounders including age, sex, BMI, smoking, education level and total energy intake. Asthma risk did not change materially after further adjustment for T2D (HR 1.91; 95\% CI 1.37, 2.66, P<0.001) (Table 3). Among $>$ once/d $v$. seldom/never consumers, the asthma association ( $41 \%$ higher) approached statistical significance ( $P=0.058$ ) (Table 3). Among 2696 participants, there were 363 incident cases of asthma over 17 years of follow-up (26 828 person-years - an incidence rate of $13.5 \%$ (Table 4). Regular (5-7 times/week) consumers of HFCS-sweetened soda had a $48 \%$ higher asthma risk (HR 1.48; $95 \%$ CI 1.09, 2.01, $P<0 \cdot 011$ ) compared with never/seldom consumers, independent of potential confounders. Asthma risk did not change materially after further adjustment for T2D (HR 1.49; 95\% CI 1.10, 2.02, $P<0 \cdot 011$ ) (Table 3).

Moderate consumers (2-4 times/week) of fruit drinks had $58 \%$ higher asthma risk (95\% CI 1.12, 2.22; $P<0.009$ ) and moderate consumers of apple juice had $61 \%$ higher asthma risk, compared with never/seldom consumers (95\% CI 1.14, $2.28 ; P<0.007)$, independent of sex, age, smoking history, education level, BMI and total energy intake. There were no significant changes in risk, after further adjustment for T2D. There was no association between diet soda or orange juice intake and asthma (Table 3).

There were 18.4 incident cases of asthma, per 1000 personyears, among frequent consumers (approximately once a day) of any combination of HFCS-sweetened soda, fruit drinks and apple juice - a number that was double that of never/seldom consumers (9.0). Persistent asthma (incident and recurrent cases) was also significantly higher with increasing consumption of high-EFF beverages (Table 4). Crude risks are available as the online Supplementary Table S1.

\section{Discussion}

Consumption of HFCS-sweetened soda, fruit drinks and apple juice - beverages with high fructose:glucose ratios - was significantly associated with increased asthma risk. There was no association with diet soda. Orange juice - a $100 \%$ juice with a 1:1 fructose:glucose ratio - and a fairly comparable 
Table 4. Asthma risk (fully adjusted) by consumption of high-fructose corn syrup (HFCS)-sweetened soft drinks, fruit drinks and apple juice (ttIEFF) in adults - The Framingham Offspring Cohort†

(Hazard ratios (HR) and $95 \%$ confidence intervals)

\begin{tabular}{|c|c|c|c|c|c|}
\hline \multirow{2}{*}{$\frac{\text { Asthma risks }}{\text { Incident }}$} & \multicolumn{5}{|c|}{ Intake frequencies } \\
\hline & \\
\hline ttlEFF & $<3 /$ month & About once/week & About 2-4 times/week & About once/d & $>$ Once/d \\
\hline Person-years & 7285 & 5492 & 4793 & 4987 & 4769 \\
\hline Cases of incident asthma & 66 & 62 & 67 & 92 & 76 \\
\hline Cases/1000 person-years & 9.0 & 11.3 & $14 \cdot 0$ & $18 \cdot 4$ & $15 \cdot 9$ \\
\hline HR fully adjusted§ & 1.00 & 1.22 & $1.61^{*}$ & $1.91^{*}$ & $1.41^{\circ}$ \\
\hline $95 \% \mathrm{Cl}$ & & $1.03,1.85$ & $1.36,2.49$ & $1.37,2.66$ & $0.99,2.02$ \\
\hline$P$ & & 0.258 & 0.008 & $<0.001$ & $<0.058$ \\
\hline \multicolumn{6}{|l|}{ Recurrent } \\
\hline ttlEFF $\ddagger$ & $<3 /$ month & About once/week & About 2-4 times/week & About once/d & $>$ Once/d \\
\hline Person-years & 8129 & 6077 & 5377 & 5618 & 5477 \\
\hline Cases recurrent asthma & 157 & 131 & 138 & 178 & 168 \\
\hline Cases per 1000 person-years & $19 \cdot 3$ & 21.5 & $25 \cdot 7$ & $31 \cdot 7$ & $30 \cdot 7$ \\
\hline HR fully adjusted§ & 1.00 & $1 \cdot 18$ & $1.52^{*}$ & $1.81^{*}$ & $1.49^{*}$ \\
\hline $95 \% \mathrm{Cl}$ & & $0.93,1.49$ & $1.20,1.92$ & $1.45,2 \cdot 26$ & $1.18,1.89$ \\
\hline$P$ & & 0.170 & $<0.001$ & $<0.001$ & 0.001 \\
\hline \multicolumn{6}{|l|}{ Incident } \\
\hline HFCS-sweetened sodał & & $\leq$ Once/week & 2-4 times/week & 5-7 times/week & $>$ Once/d \\
\hline Person-years & & 16388 & 4712 & 2987 & 3196 \\
\hline Cases of incident asthma & & 193 & 58 & 61 & 51 \\
\hline Cases/1000 person-years & & $11 \cdot 8$ & $12 \cdot 3$ & $20 \cdot 4$ & $16 \cdot 0$ \\
\hline HR fully adjusted $\|$ & & 1.00 & 1.00 & $1.49^{*}$ & 0.94 \\
\hline $95 \% \mathrm{Cl}$ & & & $0.73,1.35$ & $1 \cdot 10,2 \cdot 02$ & $0.68,1.32$ \\
\hline$P$ & & & 0.980 & 0.011 & 0.736 \\
\hline \multicolumn{6}{|l|}{ Recurrent } \\
\hline HFCS-sweetened sodał & & $\leq$ Once/week & 2-4 times/week & 5-7 times/week & > Once/d \\
\hline Person-years & & 17973 & 5247 & 3323 & 3680 \\
\hline Cases recurrent asthma & & 408 & 136 & 116 & 115 \\
\hline Cases/1000 person-years & & $22 \cdot 7$ & $25 \cdot 9$ & 34.9 & $31 \cdot 2$ \\
\hline HR fully adjusted $\|$ & & 1.00 & $1 \cdot 24^{*}$ & $1.64^{*}$ & $1 \cdot 13$ \\
\hline $95 \% \mathrm{Cl}$ & & & $1.022,1.50$ & $1.32,3.03$ & $0.91,1.41$ \\
\hline$P$ & & & 0.032 & 0.001 & 0.264 \\
\hline
\end{tabular}

* Significant associations. ${ }^{\circ}$ Association that approached significance.

$\dagger$ Incident and recurrent asthma (cases per 1000 person-years) are shown by beverage intake frequency for ttIEFF and HFCS-Sweetened soda.

$\ddagger$ Beverages with fructose:glucose ratios that exceed $1: 1^{(26)}$. The fructose:glucose ratio in apple juice is $\geq 2: 1^{(26)}$. In HFCS-sweetened soft drinks, the ratio has been measured as $1.5: 1$ for HFCS with $60 \%$ fructose ${ }^{(28)}$, and $1.9: 1$ for HFCS with $65 \%$ fructose $e^{(27)}$ - higher than the $1.2: 1$ that is generally recognised as safe ${ }^{(22,23)}$.

$\S \mathrm{HR}$ are adjusted for age, sex, education level and time-varying covariates such as BMI, history of smoking, interim smoking and type 2 diabetes.

$\|$ Analyses with HFCS-sweetened soda were further adjusted for intake frequency of non-diet fruit drinks, and apple juice, as we were interested in assessing the relative risk of asthma independent of these other high-excess free fructose beverages.

amount of total fructose $(11 \mathrm{~g})$ as non-diet soda $(14.5 \mathrm{~g})$ and apple juice $(15.7 \mathrm{~g})^{(27)}$, per 8 ounce cup $(237 \mathrm{ml})$, was also not associated with asthma, despite a higher consumption propensity ( $\geq 5$ times/week, $43.6 \%$ ) as HFCS-sweetened soda ( $\geq 5$ times/week, 31\%). The highest risk (91\%) was seen among participants who consumed any ttlEFF about once a day (5-7 times/week). However, moderate ttlEFF consumers (2-4 times/ week) were also at higher risk (61\%), relative to never/seldom consumers, independent of potential confounders, including T2D. Moderate apple juice and fruit drink consumers (2-4 times/week) also had increased asthma risk (61 and 58\% higher), as did regular consumers (5-7 times/week) of HFCS-sweetened soda ( $49 \%$ higher), relative to seldom/never consumers. It is worth noting that the asthma risk (91\%) among participants who regularly (5-7 times/week) consumed any combination of all three high-EFF beverages, relative to seldom/ never consumers, was 42 percentage points higher than the asthma risk ( $49 \%$ ) among participants who regularly consumed HFCS-sweetened soda, exclusive of fruit drinks and apple juice.

Notably, > once/day HFCS-sweetened soda intake was not associated with asthma, nor was $\geq 5$ times/week intake of fruit drink and apple juice. The association between $>$ once a day consumption of any combination of HFCS-sweetened soda, fruit drinks and apple juice and asthma approached statistical significance, albeit at a lower HR $(1.41, P=0.058)$ than among 5-7 times/week consumers $(1.91, P<0.001))$. This paradox may be due to insufficient statistical power. Another possible explanation is that persistent exposure to high immunogen (enFruAGE) concentration, over extended time periods, leads to attenuated effects over time, as chronic stimulations are known to result in a tolerogenic immune response ${ }^{(48)}$. We observed similar plateaus in our prior childhood asthma study with NHANES ${ }^{(4)}$. Interestingly, in a CDC (adult) study ( $n$ 146990), intake of SSB (HFCS-sweetened soda, fruit drinks, sports/energy drinks and sweet tea) was associated with asthma, among non-obese (BMI <30) participants. There was no association among obese (BMI $\geq 30)$ participants ${ }^{(3)}$. This is consistent with the hypothesis that persistent intakes lead to attenuated effects and immune system tolerance. In the US CDC study of high-schoolers, $\geq 3$ times/d non-diet soda intake was associated with asthma ${ }^{(2)}$. It is noteworthy that, of these studies, this (FHS-OS) analysis is the only one wherein participants were 
followed up over an extended time period (approximately 17 follow-up years) v. analyses of data from a snapshot in time.

Importantly, the lack of association with orange juice and diet soda, combined with the strong associations across all high-EFF beverages - independent of potential confounders, including T2D status - provide further evidence that the increased asthma risk may be due to the high fructose:glucose ratio in HFCS-sweetened soda, fruit drinks and apple juice. A ranking of beverages by increased asthma risk and their fructose to glucose ratios aligns well with our results as follows: (61\%) apple juice, $\geq 2: 1$; (58\%) fruit drinks (the ratio for fruit drinks likely lies somewhere between apple juice and HFCS, as many varieties are sweetened with HFCS and contain apple juice); (49\%) HFCS-sweetened soda (the ratio may be between 1.9:1 and $1 \cdot 5: 1$, depending upon fructose percentage as found by independent laboratories $\left(65 \%\right.$ fructose $^{(28)}$ and $60 \%$ fructose respectively $\left.{ }^{(29)}\right)$ ); and (None) orange juice, $1: 1^{(27)}$. The negative results with orange juice were similarly negative in our prior childhood asthma study ${ }^{(4)}$ and in the longitudinal birth cohort study - Project Viva ${ }^{(5)}$. These results support our hypothesis. Consumption of beverages with high fructose:glucose ratios (HFCS-sweetened soda, fruit drinks and apple juice) increases asthma risk, independently of blood glucose, age, sex, BMI, total energy intake, education level and smoking. This may be because of fructose malabsorption, and enteral formation of pro-inflammatory enFruAGE, but more studies of mechanism are needed.

Researchers have sought to understand the causes of fructose malabsorption. However, they remain inconclusive, as no glucose and fructose transporters (GLUT2) or EFF transporters (GLUT5) genetic mutations have been identified, nor is there evidence that depressed levels of these transporters are responsible for the condition ${ }^{(18-21)}$. Rather, research suggests that our current food supply contains EFF (high fructose: glucose ratios), from HFCS, agave syrup, crystalline fructose, apple juice and other combination juices with apple juice, that we have not evolved to consume ${ }^{(19,20)}$. Notably, the list of foods that naturally contain high fructose:glucose ratios is short. It includes primarily apples, watermelons, pears and mangoes ${ }^{(27)}$.

Although HFCS-sweetened soda and fruit drinks are major sources of EFF - the fructose type associated with fructose malabsorption $^{(18-21,49,50)}$ - the potential for a further asthma effect from intake of HFCS-sweetened foods is possible, as HFCS has been ubiquitous in the US food supply since the $1990 s^{(30-34)}$, and foods other than beverages have been more significant sources of HFCS for some people. This becomes evident with a comparison of average per capita daily HFCS intake $(65 \mathrm{~g})^{(24,30,31,51,52)}$ relative to average daily HFCS intake derived from 'SSB' ${ }^{(43,44)}$. For example, a $20 \mathrm{oz}(590 \mathrm{ml})$ bottle of cola, coincidentally, contains $65 \mathrm{~g}$, that is $1004 \mathrm{~kJ}(240 \mathrm{kcal})$, from $\operatorname{HFCS}^{(14,15)}$ - the same amount as average per capita daily HFCS intake $(65 \mathrm{~g})$, as reported before industry-influenced increases in consumer-level loss allowances ${ }^{(51-54)}$. Notably, only adolescent boys $(1142 \mathrm{~kJ} / \mathrm{d}(273 \mathrm{kcal} / \mathrm{d}))$ and men aged 20-39 years $(1054 \mathrm{~kJ} / \mathrm{d}(252 \mathrm{kcal} / \mathrm{d}))$ consumed this amount of HFCS $(\mathrm{kJ} / \mathrm{d}(\mathrm{kcal} / \mathrm{d}))$ from SSB, whereas intakes by other age $/$ sex groups ranged from $176 \mathrm{~kJ} / \mathrm{d}(42 \mathrm{kcal} / \mathrm{d})$ for women aged $\geq 60$ years to $590 \mathrm{~kJ} / \mathrm{d}(141 \mathrm{kcal} / \mathrm{d})$ for 6 - to 11 -year-old boys ${ }^{(43,44)}$. Therefore, this study may be underestimating the true asthma risk associated with HFCS intake, as HFCS as a preferred sweetener was not exclusive to beverages. Its use became ubiquitous during the time period of this study ${ }^{(30,31,33,34)}$. Notably, these HFCS intake levels from SSB were measured during a time (2005-2008) when average HFCS intake was lower than peak (approximately $80 \mathrm{~g} \mathrm{p} / \mathrm{d}, 1999)^{(24,51-54)}$, as reported before retroactively applied subjective increases in consumer-level loss allowances ${ }^{(51-54)}$.

Enrolment in the FHS-OS $(1971-1975)^{(40)}$ preceded widespread use of HFCS. However, by 1984, average per capita intake had increased to approximately $20 \mathrm{~g} / \mathrm{d}$, and later to approximately $80 \mathrm{~g} / \mathrm{d}(>1 \mathrm{lb} / \text { week })^{(24,51-54)}$. In average daily intake of $65 \mathrm{~g}$ of HFCS, there are 13-19g of EFF, depending on the fructose percentage $\left(60 \%^{(29)}\right.$ or $\left.65 \%^{(28)}\right)$. From a fructose malabsorption perspective, these levels appear problematic, given that fructose levels as low as $12.5-25 \mathrm{~g}$ are associated with adult fructose malabsorption ${ }^{(18-21,55-59)}$, and given that one cup of apple juice contributes another 8-9 g of EFF to the daily EFF load from $\mathrm{HFCS}^{(27)}$. Limited fructose malabsorption research with children indicates that they test positive at lower intakes $^{(49,50)}$.

The fate of unabsorbed EFF in the intestines has recently been tested. Incubation of amino acids ${ }^{(16)}$ and ovalbumin (a model egg protein) ${ }^{(17)}$ with fructose - but not glucose - at concentrations and $\mathrm{pH}$ that would be present in the intestines after a meal led to a time- and dose-dependent formation of FruAGE intermediates, as measured by fluorescence, within $30 \mathrm{~min}^{(17)}$ and $1 \mathrm{~h}^{(16)}$ of incubation - a time frame well compatible with the digestive process. This provides evidence that fructose malabsorption may underlie the intestinal in situ formation of pro-inflammatory FruAGE. These end products may initiate a cascade of symptoms, including airway mucous hypersecretion that promotes asthma ${ }^{(1)}$. Although RAGE are located in many tissues, the lungs have the highest concentration $^{(35)}$, and evidence suggests that they are mediators of asthma ${ }^{(36)}$. There is evidence that glycated peptides, seven amino acids long, with ne-carboxy-methyl-lysine (CML) and ne-carboxy-ethyl-lysine - well-studied AGE - were capable of triggering pro-inflammatory cytokine gene expression, without requiring a specific amino acid sequence ${ }^{(60,61)}$. This is important, as conditions in the intestines, with proteins at various digestion levels, may be conducive to the formation and absorption of a potentially large quantity of heterogeneous glycated peptides. Because of their small size, these extracellular newly identified enFruAGE may leave the vascular compartment and trigger pro-inflammatory signalling that increases asthma risk. Since the discovery that receptors of AGE are mediators of asthma, additional studies have confirmed that RAGE are major mediators of pulmonary inflammatory responses across pulmonary conditions ${ }^{(62)}$.

Most recently, results of another in vitro study, with meal resembling systems, provided further evidence that FruAGE may form in the intestines. Their results showed that only the meal with fructose (as remains in the intestines of fructose malabsorbers) formed CML, and it occurred well within the time window of digestion $(1 \mathrm{~h})$. There was no CML formation with glucose $^{(63)}$. This research provided further evidence that these 
intestinally formed immunogens may accumulate in body tissues and contribute to asthma and its comorbidities ${ }^{(1,7)}$. Notably, asthma patients have increased risk of $\mathrm{CHD}^{(47,64)}$, rheumatoid arthritis ${ }^{(65)}$ and $\mathrm{T}_{2} \mathrm{D}^{(66)}$, for reasons that remain inconclusive. In prior studies, we found that intakes of non-diet soda, fruit drinks and apple juice, but not diet soda ${ }^{(67)}$ or $100 \%$ orange juice ${ }^{(68)}$, were associated with idiopathic arthritis ${ }^{(67)}$ and $\mathrm{CHD}^{(68)}$. Furthermore, the paradox in dietary AGE (dAGE) research provides indirect support for this hypothesis. Serum and urinary AGE were not associated with intake of foods previously thought to be high in dAGE (fast foods, hamburgers and fries), as hypothesised. Rather, the association was with intake of HFCSsweetened foods, including cold cereals, breads and sweets ${ }^{(69)}$.

The results of this study, along with others, have important implications for public policy. They support the possibility that the $100 \%$ juice reductions in the US Special Supplemental Nutrition Program for Women, Infants, and Children (WIC) in $2009^{(70,71)}$, and the plateauing/decreasing asthma prevalence seen in 2010-2013, particularly among non-Hispanic black children $^{(72)}$, may be related. WIC is a federally supported nutrition assistance programme that serves $>$ one-quarter of the pregnant women, half the infants and many children $<5$ years of age in the $\mathrm{USA}^{(70,71)}$. The 2009 revision eliminated $100 \%$ juice from the infants food package, and reduced quantities for women and children ${ }^{(71)}$. Furthermore, in a recent report by the US CDC, childhood asthma prevalence doubled from 1980 to 1995 (a period with a rapid rise in average per-capita HFCS consumption) and then increased more slowly from 2001 to 2010. The increase from 2001 to 2009 was followed by a plateau and then a decline in 2013. Researchers noted that current asthma prevalence ceased to increase among children in recent years and that the non-Hispanic black-white disparity stopped increasing, mainly owing to plateauing prevalence among non-Hispanic black children ${ }^{(72)}$. Although soft drink consumption has declined over the past decade ${ }^{(43,44)}$, our prior childhood (ages 2-9 years) asthma study results with nationally representative NHANES data from 2003 to $2006^{(4)}$ suggest that the asthma decline, among non-Hispanic black children in 2012, may be more attributed to the decline in apple juice consumption than soft drink consumption, as moderate apple juice consumers were more than two and a half times as likely to have asthma as compared with seldom/never consumers, whereas intake of non-diet soda was associated with asthma prevalence, only when consumed in combination with apple juice and fruit drinks $^{(4)}$.

Results of another study were recently published wherein early childhood fructose intake was associated with midchildhood asthma, independent of $\mathrm{BMI}^{(73)}$. However, this research is a re-analysis of an earlier study (2014), of the same mother-child pairs (Project Viva) ${ }^{(5)}$. In the first published study, researchers found that intake of juice at 2 years of age, excluding orange juice, was associated with mid-childhood asthma $^{(5)}$. In the re-analysis, no distinction was made between orange juice and apple juice. Researchers concluded in both analyses that the asthma association is with total fructose ${ }^{(5,73)}$. However, this interpretation is inconsistent with their earlier results $^{(5)}$. Importantly, it is inconsistent with this study's results, with findings from our analysis with $\operatorname{NHANES}^{(4,7)}$ and with the case study that motivated this research ${ }^{(1)}$. Furthermore, across epidemiological studies, associations are independent of BMI, providing evidence that mechanisms are independent of adiposity $^{(2-5,73)}$. Importantly, CDC researchers recently assessed whether population-level changes in weight status affected asthma prevalence trends over time (1988-2014 NHANES). They found that, although obesity was a risk factor for asthma throughout the period, asthma prevalence increased only among children with normal weight. They concluded that the data do not support a contribution of obesity trends to increasing asthma prevalence trends ${ }^{(74)}$. The results presented herein support the hypothesis that the asthma association is with fructose to glucose ratios that exceed 1:1 (EFF), with underlying fructose malabsorption, and with formation of asthma-triggering immunogens in the GI lumen between unabsorbed EFF and partially digested dietary peptides.

This study has limitations. First, outcomes were based on selfreport, which is subject to reporting bias. However, these results are consistent with existing studies, and with another recently published cross-sectional study of US adults with doctordiagnosed current asthma. Individuals with doctor-diagnosed active asthma who drank non-diet soda three or more times/ week had higher odds $(2 \cdot 8 ; 95 \%$ CI $1 \cdot 51,5 \cdot 10, P=0 \cdot 001)$ of overnight hospitalisation compared with seldom consumers, independent of age, education, sex, race/ethnicity, weight status, smoking and self-rated health ${ }^{(75)}$. Second, a myriad of foods contribute to EFF intake (cold cereals, breads, snack bars, desserts, sweets, ketchup, sauces and so on) ${ }^{(30-34)}$, which were not accounted for in this study. Foods, other than beverages, are major sources of HFCS for many age groups, as adolescent boys and men aged 20-39 years were the only ones consuming SSB at levels consistent with HFCS average per-capita consumption ${ }^{(43,44)}$. Foods sweetened with agave syrup and crystalline fructose were also not considered. This exposure underestimation may have attenuated our ability to quantify the true risk. Third, this study is not nationally representative. Participants were mainly non-Hispanic white Americans, which does not allow consideration of race/ethnicity on this relationship. In particular, we may be underestimating the true risk among African Americans as they have higher fructose malabsorption prevalence than non-Hispanic whites and Hispanics ${ }^{(76)}$. However, in existing studies, associations with asthma were independent of race/ethnicity ${ }^{(2-5,58)}$. Fourth, although we were able to adjust for education level, we were not able to account for income - a possible confounder - as it was not available. However, in our prior studies of childhood asthma ${ }^{(4)}$, and adult chronic bronchitis ${ }^{(37)}$, associations were independent of socioeconomic status. Fifth, we were not able to assess occupational or environmental air quality factors as a potential confounder, as this information was not available in the data. Sixth, this study with adults did not quantify risks in children. More research is needed, particularly with children, as fructose malabsorption research indicates that they test positive at lower intakes ${ }^{(49,50)}$. Seventh, we were unable to assess associations before 1984, to test the hypothesis that non-diet soda, when sweetened with sucrose, is not associated with asthma, as examinations 1 and 2 lacked an FFQ. More biochemical, clinical and consequences of fructose malabsorption research is needed. 


\section{Conclusion}

Moderate and frequent consumption of HFCS-sweetened soda, fruit drinks and apple juice, but not diet soda or orange juice, increased asthma risk, independent of age, sex, smoking, BMI, education level, total energy intake and T2D. This may be because of the high fructose:glucose ratio in these beverages, fructose malabsorption and formation of asthma-triggering immunogens (enFruAGE) in the GI lumen. Recommendations to reduce sugarsweetened beverage consumption may be inadequate to address asthma risk, as associations are evident even with moderate intake of apple juice - a $100 \%$ juice. The $100 \%$ juice reductions in the WIC in 2009, and the plateauing/decreasing asthma prevalence (2010-2013), particularly among non-Hispanic black children, may be related. Intervention studies and more research of consequences of fructose malabsorption are needed.

\section{Acknowledgements}

The FHS is funded by the National Heart, Lung and Blood Institute (HHSN268201500001I; NO1-HC-25195; HL076784; AG028321; HL070100; HL060040; HL080124; HL071039; HL077447; 6R01-NS-17950; and HL107385). This research received no specific grant from any funding agency, commercial or not-for-profit sectors.

L. R. D. C. researched and developed the biochemical hypothesis, designed the epidemiology research, performed all of the analyses and wrote the manuscript. L. R. D. C. holds a Master's of Science in Biochemistry, Molecular Biology, New York Medical College, Valhalla, NY; she has additionally completed advanced coursework in immunology, epidemiology and biostatistics. K. L. T. provided critical review, reviewed all statistical analyses and contributed to editing the manuscript. All authors read and approved the final manuscript.

The authors declare that there are no conflicts of interest.

\section{Supplementary material}

For supplementary material/s referred to in this article, please visit https://doi.org/10.1017/S0007114518000417

\section{References}

1. DeChristopher LR (2012) Consumption of fructose and high fructose corn syrup: is fructositis triggered bronchitis, arthritis, \& auto-immune reactivity merely a side bar in the etiology of metabolic syndrome II (to be defined)? - evidence and a hypothesis. https://www.researchgate.net/publication/276920662 (accessed February 2018).

2. Park S, Blanck HM, Sherry B, et al. (2013) Regular-soda intake independent of weight status is associated with asthma among US high school students. I Acad Nutr Diet 113, 106-111.

3. Park S, Akinbami LJ, McGuire LC, et al. (2016) Association of sugar-sweetened beverage intake frequency and asthma among U.S. adults, 2013. Prev Med $\mathbf{9 1}$, 58-61.

4. DeChristopher LR, Uribarri J \& Tucker KL (2016) Intakes of apple juice, fruit drinks and soda are associated with prevalent asthma in US children aged 2-9 years. Public Health Nutr 19, 123-130.

5. Wright LS, Rifas-Shiman S, Oken E, et al. (2015) Maternal prenatal intake of fructose is associated with asthma in children. J Aller Clin Immunol 135, AB228.
6. National Institute of Allergy and Infectious Diseases of the National Institute of Health (2011) Guidelines for the Diagnosis and Management of Food Allergy in the United States. Bethesda, MD: US Department of Health and Human Services. https://nihpublications.od.nih.gov/Publication Details.aspx?PubID=6391 (accessed February 2018).

7. DeChristopher LR, Uribarri J \& Tucker KL (2016) The link between soda intake and asthma: science points to the highfructose corn syrup, not the preservatives: a commentary. Nutr Diabetes 6, e234.

8. Coca Cola New Zealand (2015) http://www.coca-colajourney. co.nz/brands/coca-cola (accessed May 2015).

9. Wickens K, Barry D, Friezema A, et al. (2005) Fast foods - are they a risk factor for asthma? Allergy 60, 1537-1541.

10. Shi Z, Dal Grande E, Taylor AW, et al. (2012) Association between soft drink consumption and asthma and chronic obstructive pulmonary disease among adults in Australia. Respirology 17, 363-369.

11. Watkins NG, Neglia-Fisher CI, Dyer DG, et al. (1987) Effect of phosphate on the kinetics and specificity of glycation of protein. J Biol Chem 262, 7207-7212.

12. Zhang Q, Ames JM, Smith RD, et al. (2009) A perspective on the Maillard reaction and the analysis of protein glycation by mass spectrometry: probing the pathogenesis of chronic disease. J Proteome Res 8, 754-769.

13. Rizzi GP (2004) Role of phosphate and carboxylate ions in Maillard browning. J Agric Food Chem 52, 953-957.

14. The Coca Cola Company (2016) http://www.coca-colaproductfacts.com/en/coca-cola-ingredients/\#glossary-S (accessed May 2016).

15. Pepsico (2016) http://www.pepsicobeveragefacts.com/home/ ingredientglossary\#S (accessed May 2016).

16. Bains Y \& Gugliucci A (2016) Ilex paraguariensis and its main component chlorogenic acid inhibit fructose formation of advanced glycation endproducts with amino acids at conditions compatible with those in the digestive system. Fitoterapia. 117, 6-10.

17. Bains Y, Gugliucci A \& Caccavello R (2017) Advanced glycation endproducts form during ovalbumin digestion in the presence of fructose: inhibition by chlorogenic acid. Fitoterapia 120, 1-5.

18. Riby JE, Fujisawa T \& Kretchmer N (1993) Fructose absorption. Am J Clin Nutr 58, 5 Suppl., 748S-753S.

19. Gibson PR, Newnham E, Barrett JS, et al. (2007) Review article: fructose malabsorption and the bigger picture. Aliment Pharmacol Ther 25, 349-363.

20. Biesiekierski JR (2014) Fructose-induced symptoms beyond malabsorption in FGID. United Eur Gastroenterol J. 2, 10-13.

21. Ebert K \& Witt H (2016) Fructose malabsorption. Mol Cell Pediatr 3, 10.

22. United States Food \& Drug Administration (2017) Code of Federal Regulations Title 21, Volume 3. 21CFR184.1866. https://www. accessdata.fda.gov/scripts/cdrh/cfdocs/cfcfr/CFRSearch.cfm? $\mathrm{fr}=184.1866$ (accessed February 2018).

23. Federal Register (1996) Rules and regulations, Volume 61, Number 165, 23 August, pp. 43447, 43450. FR Doc No.: 9621482. https://www.gpo.gov/fdsys/pkg/FR-1996-08-23/ html/96-21482.htm (accessed December 2017).

24. US Department of Agriculture \& Economic Research Service (2012) The ERS food availability (Per Capita) data system. http:// www.ers.usda.gov/data-products/food-availability-(per-capita)data-system.aspx $\#$

25. Mellado-Mojica E \& López MG (2015) Identification, classification, and discrimination of agave syrups from natural sweeteners by infrared spectroscopy and HPAEC-PAD. Food Chem 167, 349-357. 
26. Willems JL \& Low NH (2012) Major carbohydrate, polyol, and oligosaccharide profiles of agave syrup. Application of this data to authenticity analysis. J Agric Food Chem 60, 8745-8754.

27. US Department of Agriculture \& Agricultural Research Service (2012) USDA National Nutrient Database for Standard Reference, Release 26. http://www.ars.usda.gov/ba/bhnrc/ndl (accessed December 2015).

28. Ventura EE, Davis JN \& Goran MI (2011) Sugar content of popular sweetened beverages based on objective laboratory analysis: focus on fructose content. Obesity (Silver Spring) 19, 868-874.

29. Walker RW, Dumke KA \& Goran MI (2014) Fructose content in popular beverages made with and without high-fructose corn syrup. Nutrition 30, 928-935.

30. Morrison R, M \& Buzby JC (2010) Guess who's turning 100? Tracking a century of American eating. Washington, DC: US Department of Agriculture, Economic Research Service, Amber Waves. https://www.ers.usda.gov/amber-waves/2010/march/ guess-who-s-turning-100tracking-a-century-of-american-eating/ (accessed December 2015).

31. Wells HF \& Buzby JC (2008) High-fructose corn syrup usage may be leveling off. Washington, DC: US Department of Agriculture, Economic Research Service. https://www.ers.usda. gov/amber-waves/2008/february/high-fructose-corn-syrup-usagemay-be-leveling-off/ (accessed December 2015).

32. Duffey KJ \& Popkin BM (2008) High-fructose corn syrup: is this what's for dinner? Am J Clin Nutr 88, 1722S-1732S.

33. Bray GA (2013) Energy and fructose from beverages sweetened with sugar or high-fructose corn syrup pose a health risk for some people. Adv Nutr 4, 220-225.

34. Bray GA, Nielsen SJ \& Popkin BM (2004) Consumption of high-fructose corn syrup in beverages may play a role in the epidemic of obesity. Am J Clin Nutr 79, 537-543.

35. Buckley ST \& Ehrhardt C (2010) The receptor for advanced glycation end products (RAGE) and the lung. J Biomed Biotechnol 2010, 917108.

36. Milutinovic PS, Alcorn JF, Englert JM, et al. (2012) The receptor for advanced glycation end products is a central mediator of asthma pathogenesis. Am J Pathol 181, 1215-1225.

37. DeChristopher LR, Uribarri J \& Tucker KL (2015) Intake of high fructose corn syrup sweetened soft drinks is associated with prevalent chronic bronchitis in U.S. Adults, ages 20-55 y. Nutr J 14, 107.

38. Berentzen NE, van Stokkom VL, Gehring U, et al. (2015) Associations of sugar-containing beverages with asthma prevalence in 11-year-old children: the PIAMA birth cohort. Eur J Clin Nutr 69, 303-308.

39. DeChristopher LR (2015) Excess free fructose and childhood asthma. Eur J Clin Nutr 69, 1371.

40. The Framingham Heart Study (2017) A project of the National Heart, Lung, and Blood Institute and Boston University. http:// www.framinghamheartstudy.org/ (accessed February 2018).

41. Warner M (2006) A sweetener with a bad rap. New York Times. http://www.nytimes.com/2006/07/02/business/yourmoney/02syrup.html

42. Bovard J (1998) The great sugar shaft. Freedom Daily, April. https://www.fff.org/explore-freedom/article/great-sugar-shaft/ (accessed February 2018).

43. Han E \& Powell LM (2013) Consumption patterns of sugarsweetened beverages in the United States. J Acad Nutr Diet 113, 43-53.

44. Ogden CL, Kit BR, Carroll MD, et al. (2011) Consumption of sugar drinks in the United States, 2005-2008. NCHS Data Brief. http://www.cdc.gov/nchs/data/databriefs/db71.htm (accessed February 2018).

45. Vartanian LR, Schwartz MB \& Brownell KD (2007) Effects of soft drink consumption on nutrition and health: a systematic review and meta-analysis. Am J Public Health 97, 667-675.

46. Yun HD, Knoebel E, Fenta Y, et al. (2012) Asthma and proinflammatory conditions: a population-based retrospective matched cohort study. Mayo Clin Proc 87, 953-960.

47. de Koning L, Malik VS, Kellogg MD, et al. (2012) Sweetened beverage consumption, incident coronary heart disease, and biomarkers of risk in men. Circulation 125, 1735-1741.

48. Pradeu T \& Vivier E (2016) The discontinuity theory of immunity. Sci Immunol 1, AAG0479.

49. Jones HF, Burt E, Dowling K, et al. (2011) Effect of age on fructose malabsorption in children presenting with gastrointestinal symptoms. J Pediatr Gastroenterol Nutr $\mathbf{5 2}$, 581-584.

50. Smith MM, Davis M, Chasalow FI, et al. (1995) Carbohydrate absorption from fruit juice in young children. Pediatrics $\mathbf{9 5}$, 340-344.

51. Haley S (2011) Sugars and sweeteners outlook. SSS-M-270. Washington, DC: US Department of Agriculture, pp. 6-9. http://usda.mannlib.cornell.edu/usda/ers/SSS//2010s/2011/ SSS-02-14-2011.pdf (accessed December 2015).

52. Haley S (2012) Sugars and sweeteners outlook. SSM-M-286. Washington, DC: US Department of Agriculture. pp. 16-19. http://usda.mannlib.cornell.edu/usda/ers/SSS//2010s/2012/ SSS-06-18-2012.pdf (accessed December 2015).

53. Strom S (2012) US cuts estimate of sugar intake. The New York Times. 26 October. http://www.nytimes.com/2012/10/27/ business/us-cuts-estimate-of-sugar-intake-of-typical-american. html (accessed December 2015).

54. Sosland J (2011) Study raises national food waste estimates. Food Business News. 4 January. http://www.foodbusinessnews.net/ News/News-Home/Consumer-Trends/2011/1/Study-raisesnational-food-waste-estimates.aspx?cck=1 (accessed December 2015).

55. Hoekstra JH, van Kempen AA, Bijl SB, et al. (1993) Fructose breath hydrogen tests. Arch Dis Child $\mathbf{6 8}$, 136-138.

56. Gomara RE, Halata MS, Newman LJ, et al. (2008) Fructose intolerance in children presenting with abdominal pain. J Pediatr Gastroenterol Nutr 47, 303-308.

57. Rumessen JJ \& Gudmand-Hoyer E (1988) Functional bowel disease: malabsorption and abdominal distress after ingestion of fructose, sorbitol, and fructose-sorbitol mixtures. Gastroenterology 95, 694-700.

58. Rumessen JJ (1992) Fructose and related food carbohydrates. sources, intake, absorption, and clinical implications. Scand J Gastroenterol 27, 819-828.

59. Beyer PL, Caviar EM \& McCallum RW (2005) Fructose intake at current levels in the united states may cause gastrointestinal distress in normal adults. J Am Diet Assoc 105, 1559-1566.

60. Xue J, Rai V, Singer D, et al. (2011) Advanced glycation end product recognition by the receptor for AGEs. Structure 19, $722-732$.

61. Dötsch V (2011) How to create a specific recognition for an unspecific interaction. Structure 19, 601-602.

62. Oczypok EA, Perkins TN \& Oury TD (2017) All the 'RAGE' in lung disease: the receptor for advanced glycation endproducts (RAGE) is a major mediator of pulmonary inflammatory responses. Paediatr Respir Rev 23, 40-49.

63. Martinez-Saez N, Fernandez-Gomez B, Cai W, et al. (2017) In vitro formation of Maillard reaction products during simulated digestion of meal-resembling systems. Food Res Int (Epublication ahead of print version 21 September 2017).

64. Iribarren C, Tolstykh IV, Miller MK, et al. (2012) Adult asthma and risk of coronary heart disease, cerebrovascular disease, 
and heart failure: a prospective study of 2 matched cohorts. Am J Epidemiol 176, 1014-1024.

65. Patel MR, Janevic MR, Heeringa SG, et al. (2013) An examination of adverse asthma outcomes in U.S. Adults with multiple morbidities. Ann Am Thorac Soc 10, 426-431.

66. Song Y, Klevak A, Manson JE, et al. (2010) Asthma, chronic obstructive pulmonary disease, and type 2 diabetes in the Women's Health Study. Diabetes Res Clin Pract 90, 365-371.

67. DeChristopher LR, Uribarri J \& Tucker KL (2016) Intake of high-fructose corn syrup sweetened soft drinks, fruit drinks and apple juice is associated with prevalent arthritis in US adults, aged 20-30 years. Nutr Diabetes 6, e199.

68. DeChristopher LR, Uribarri J \& Tucker KL (2017) Intake of high fructose corn syrup sweetened soft drinks, fruit drinks and apple juice is associated with prevalent coronary heart disease, in US adults, ages 45-59 y. BMC Nutr 3, 51.

69. DeChristopher LR (2017) Perspective: the paradox in dietary advanced glycation end-products research: the source of the elevated serum and urinary AGEs is the intestines, not the food. Adv Nutr 8, 679-683.

70. Oliveira V \& Frazao E (2015) The WIC Program: Background, Trends, and Economic Issues, 2015 Edition. Economic Information Bulletin no. 134. Washington, DC: US Department of Agriculture, Economic Research Service. https://www.aap.
org/en-us/advocacy-and-policy/federal-advocacy/Documents/ USDAWIC2015Report.pdf (accessed February 2018).

71. US Department of Agriculture Food and Nutrition Service (2011) WIC Food Packages Policy Options Study Final Report. Report no. WIC-11-FOOD. US Department of Agriculture Food and Nutrition Service, Nutrition Assistance Program Report Series, Office of Research and Analysis, Special Nutrition Programs, June. http://www.fns.usda.gov/sites/default/ files/WICFoodPackageOptions.pdf (accessed February 2018).

72. Akinbami LJ, Simon AE \& Rossen LM (2016) Changing trends in asthma prevalence among children. Pediatrics 137, 1-7.

73. Wright LS, Rifas-Shiman SL, Oken E, et al. (2018) Prenatal and early-life fructose, fructose-containing beverages, and midchildhood asthma. Ann Am Thorac Soc 15, 217-224.

74. Akinbami LJ, Rossen LM, Fakhouri THI, et al. (2017) Asthma prevalence trends by weight status among US children aged 2-19 years, 1988-2014. Pediatr Obes (Epublication ahead of print version 12 November 2017).

75. Cisneros R, Gonzalez M, Brown P, et al. (2016) Soda consumption and hospital admissions among Californian adults with asthma. J Asthma 5, 1-5.

76. Walker RW, Lê KA, Davis J, et al. (2012) High rates of fructose malabsorption are associated with reduced liver fat in obese African Americans. J Am Coll Nutr 31, 369-374. 